03,05

\title{
Электрические и магнитные свойства дисульфида гафния, интеркалированного атомами железа
}

\author{
(C) В.Г. Плещев, Н.В. Селезнева
}

Институт естественных наук и математики Уральского федерального университета им. Б.Н. Ельцина, Екатеринбург, Россия

E-mail: v.g.pleshchev@urfu.ru

(Поступила в Редакцию 3 июля 2017 г.)

Впервые проведено совместное исследование зависимостей структурных параметров, электрических и магнитных свойств дисульфида гафния, интеркалированного атомами железа, в зависимости от концентрации интеркалянта и температуры. Показано, что температурные зависимости электросопротивления имеют активационный характер с энергиями активации, характерными для примесной проводимости. Обнаружено, что эффективные магнитные моменты ионов железа в $\mathrm{Fe}_{x} \mathrm{HfS}_{2}$ оказываются значительно меньшими, чем значения для свободных ионов железа, и уменьшаются при возрастании содержания железа. Характер температурных зависимостей эффективных магнитных моментов и отрицательные значения парамагнитных температур Кюри указывают на возможные взаимодействия антиферромагнитного типа между интеркалированными атомами. Однако зависимости намагниченности от поля для $\mathrm{Fe}_{0.33} \mathrm{HfS}_{2}$ и $\mathrm{Fe}_{0.5} \mathrm{HfS}_{2}$, полученных при $T=2 \mathrm{~K}$, демонстрируют гистерезисные явления, свойственные ферромагнитному состоянию. Полученные результаты обсуждаются в предположении о наличии гибридизации $3 d$-электронных состояний интеркалированных атомов железа с электронными состояниями матриц $\mathrm{HfS}_{2}$ и конкуренции обменных взаимодействий разного типа.

Настоящая работа выполнена при финансовой поддержке Министерства образования и науки РФ (проект № 3.2916.2017/4.6).

DOI: $10.21883 /$ FTT.2018.02.45375.219

\section{1. Введение}

Дихалькогениды гафния $\mathrm{Hf}_{2}(X=\mathrm{S}, \mathrm{Se}, \mathrm{Te})$ принадлежат к достаточно обширному классу соединений с квазидвумерной кристаллической структурой, относящейся к структурному типу $\mathrm{CdJ}_{2}[1,2]$. Особенностью такой структуры является наличие слабой ван-дер-ваальсовой связи между $X-\mathrm{Hf}-X$ трехслойными блоками, что позволяет внедрять в межслоевое пространство атомы других элементов. Внедрение (интеркаляция) в незанятые позиции между слоями атомов $3 d$-переходных элементов, обладающих незаполненными электронными оболочками, позволяет получать структуры с чередующимися слоями „магнитных“ и немагнитных атомов. Изменяя концентрацию интеркалированных магнитных атомов разного сорта, можно в широких пределах варьировать обменные взаимодействия внутри слоя и между слоями и формировать магнитные упорядочения различного типа. Среди подобных соединений наиболее изученными являются дихалькогениды титана и материалы на их основе. В них выявлен широкий спектр магнитных состояний в зависимости от концентрации и сорта внедренных атомов, а также от типа халькогена в $\mathrm{TiX}_{2}[3,4]$. Возникновение магнитного упорядочения в подобных соединениях со слоистой структурой обусловлено комбинацией двух типов обменных взаимодействий между $3 d$-электронами внедренных атомов: косвенное взаимодействие через электроны проводимости внутри слоя по механизму РККИ и сверхобменное взаимодействие между слоями через атомы халькогена [5].

Хотя $\mathrm{HfS}_{2}$ является химическим и структурным аналогом дисульфида титана, однако существенно отличается своими кристаллографическими характеристиками и электронным строением. Вследствие увеличения параметров элементарной ячейки у дисульфида гафния по сравнению с $\mathrm{TiS}_{2}$ взаимодействие между слоями $\mathrm{HfS}_{2}$ должно быть еще более ослабленным, а двумерный характер его структуры проявляться в большей степени. В работах, посвященных анализу электронной структуры дихалькогенидов гафния, сообщается, что дисульфид гафния обладает значительной величиной запрещенной зоны, величина которой составляет около $1.9 \mathrm{eV}[1,6]$.

При исследовании электрических свойств дисульфида гафния было обнаружено, что в зависимости от электрической предыстории (при возрастании или уменьшении напряженности электрического поля) этот материал характеризовался различными значениями электросопротивления и даже проявлял отрицательную вольтамперную характеристику [7]. Подобные эффекты, зависящие от времени, были также получены в соединениях $\mathrm{Cu}_{x} \mathrm{HfSe}_{2}[8]$.

Электрические свойства образцов дисульфида гафния, интеркалированных атомами серебра, нами ранее исследовались в постоянных и переменных электрических полях [9]. Полученные результаты указывают на то, что проводимость на переменном токе испытывает частотную дисперсию, которая описывается „универсальным 
динамическим откликом“ (UDR) [10]. При этом было показано, что релаксационные процессы в переменном поле ускоряются при возрастании содержания серебра в образцах и при увеличении температуры.

Сведения о магнитных свойствах соединений на основе дисульфида гафния в литературе практически отсутствуют. Вместе с тем известно, что в подобных соединениях $\mathrm{Fe}_{x} \mathrm{TiS}_{2}$ для состава $x=0.5$ при $T=2 \mathrm{~K}$ была обнаружена высокая коэрцитивная сила $25 \mathrm{kOe}$ [11], а при $x=2 / 3$ до $40 \mathrm{kOe}[12]$. Вследствие увеличения расстояния между интеркалированными атомами, внедренными между слоями $\mathrm{HfS}_{2}$, интенсивность сверхобменных взаимодействий, имеющих, как правило, антиферромагнитный характер, будет уменьшаться. В этом случае более значительную роль может играть обмен через электроны проводимости по механизму РККИ, носящий знакопеременный характер и при определенных условиях способный обеспечить магнитоупорядоченное состояние. В этом случае важную роль приобретают характеристики электронного переноса данной системы, ответственные за природу взаимодействия между магнитоактивными ионами.

Таким образом, имеющиеся немногочисленные данные свидетельствуют о том, что соединения на основе дихалькогенидов гафния представляют не только научный, но и практический интерес. В связи с этим настоящая работа посвящена исследованию электрических и магнитных свойств интеркалированных соединений в системе $\mathrm{Fe}_{x} \mathrm{HfS}_{2}$.

\section{2. Эксперимент}

Синтез исходного диселенида гафния и интеркалированных образцов $\mathrm{Fe}_{x} \mathrm{HfS}_{2}(0 \leq x \leq 0.5)$ производился методом твердофазных реакций в вакуумированных кварцевых ампулах, который ранее применялся для получения интеркалированных соединений на основе дихалькогенидов титана [13]. В качестве исходных материалов были использованы металлический гафний, полученный иодидным способом, карбонильное металлическое железо и сера марки ОСЧ.

Аттестация полученных материалов производилась рентгенографически на дифрактометре Bruker D8 Advance. В результате многократной гомогенизации, которая проводилась при температуре $800^{\circ} \mathrm{C}$, удалось добиться практически однофазного состояния. Лишь небольшое количество двуокиси гафния (не более 5\%) было обнаружено в полученных образцах. В табл. 1 содержатся данные о параметрах элементарной ячейки основной фазы, соответствующей структуре $1 \mathrm{~T}-\mathrm{HfS}_{2}$, в синтезированных образцах. Значения параметров для $\mathrm{HfS}_{2}$ находятся в хорошем согласии с имеющимися данными $[1,6]$. Сравнительно небольшое уменьшение параметров при возрастании содержания интеркалированных атомов может быть связано с взаимодействием между атомами железа и слоями матрицы.
Таблица 1. Параметры элементарной ячейки $a$ и $c$ образцов $\mathrm{Fe}_{x} \mathrm{HfS}_{2}$

\begin{tabular}{l|c|c}
\hline Образец & $a, \mathrm{~nm}$ & $c, \mathrm{~nm}$ \\
\hline $\mathrm{HfS}_{2}$ & $0.3627(2)$ & $0.5842(2)$ \\
$\mathrm{Fe}_{0.2} \mathrm{HfS}_{2}$ & $0.3621(1)$ & $0.5842(2)$ \\
$\mathrm{Fe}_{0.25} \mathrm{HfS}_{2}$ & $0.3620(8)$ & $0.5840(5)$ \\
$\mathrm{Fe}_{0.5} \mathrm{HfS}_{2}$ & $0.3615(2)$ & $0.5832(3)$
\end{tabular}

Измерения физических свойств проводились на поликристаллических образцах после дополнительного прессования и спекания. Магнитные характеристики определялись методом Фарадея в интервале 80-298 K и с помощью СКВИД-магнитометра (MPMS) в области температур 2-350 К и в магнитных полях до $70 \mathrm{kOe}$. Измерения электросопротивления производилось в интервале температур 150-350 К на поликристаллических образцах в форме параллелепипеда. Предварительная оценка электрических характеристик полученных образцов показала их высокое электросопротивление, что не позволяло обеспечить хорошее качество потенциальных контактов при использовании стандартного двухзондового метода. В связи с этим для измерений электросопротивления был использован метод амперметра-вольтметра. На торцовые поверхности образцов наносилась проводящая паста, что обеспечивало их эквипотенциальность и одинаковость значений тока по сечению образцов.

\section{3. Результаты}

В работе были впервые получены результаты по температурной зависимости электросопротивления дисульфида гафния, интеркалированного железом. При использовании метода амперметра-вольтметра, где измеряемая разность потенциалов включает и падение напряжения на токовых контактах, важным является установление омического характера используемых контактов. С этой целью нами были проведены измерения вольтамперных характеристик (BAX) образцов различного состава при циклическом $\left(0 \rightarrow U_{\max } \rightarrow 0 \rightarrow-U_{\max } \rightarrow 0\right)$ изменении приложенной разности потенциалов. Данные, полученные при комнатной температуре, представлены на рис. 1. Как видно, эти характеристики являются линейными в широкой области приложенных напряжений, величины которых были использованы для измерений температурных зависимостей электросопротивления. Изменение резистивного состояния исследуемых материалов по мере понижения температуры также может оказывать влияние на состояние контактов. В связи с этим нами были измерены ВАХ образцов при различных температурах. На рис. 2 в качестве примера показаны вольтамперные характеристики образца $\mathrm{Fe}_{0.2} \mathrm{HfS}_{2}$, измеренные при более низких температурах, которые также свидетельствуют об отсутствии каких-либо нелинейных 
эффектов на границах электрод-образец. Таким образом, линейный и обратимый характер ВАХ свидетельствуют о хорошем качестве используемых контактов и делают полученные в дальнейшем результаты достоверными.

Температурные зависимости удельного электросопротивления образцов, представленные на рис. 3, демонстрируют активационный характер проводимости. Можно также видеть, что при возрастании содержания железа величина электросопротивления уменьшается, что возможно связано с увеличением концентрации свободных носителей заряда за счет дополнительного внедрения атомов железа. По-видимому, этот фактор преобладает над увеличением рассеяния носителей заряда на внедренных атомах, вносящих искажения в кристаллическую структуру исходной матрицы. В результате обработки экспериментальных данных было показано, что логарифмические зависимости удельного электросопротивления от обратной температуры имели линейный характер, что соответствует постоянной энергии активации $(\Delta E)$ в исследованной области темпера-

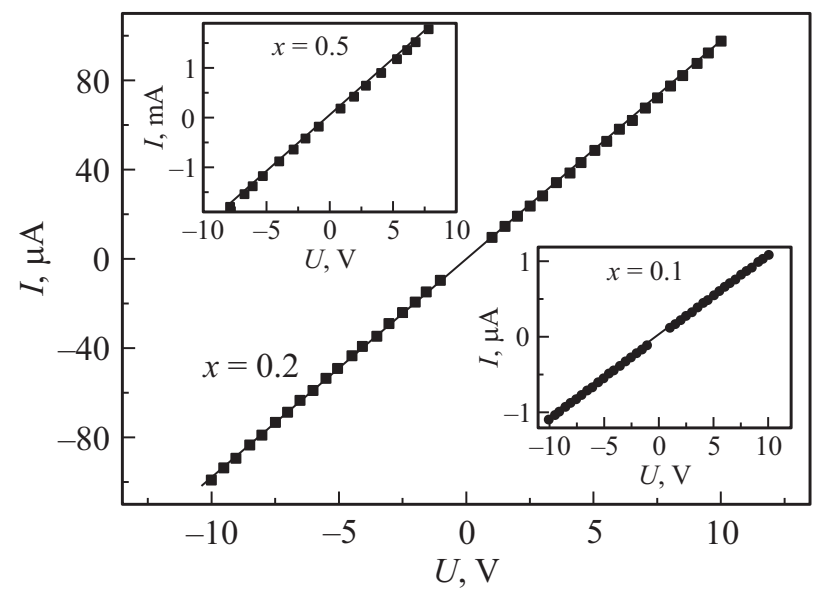

Рис. 1. Вольтамперные характеристики образцов $\mathrm{Fe}_{x} \mathrm{HfS}_{2}$ при комнатной температуре.



Рис. 2. Вольт-амперные характеристики $\mathrm{Fe}_{0.2} \mathrm{HfS}_{2}$ при различных температурах.
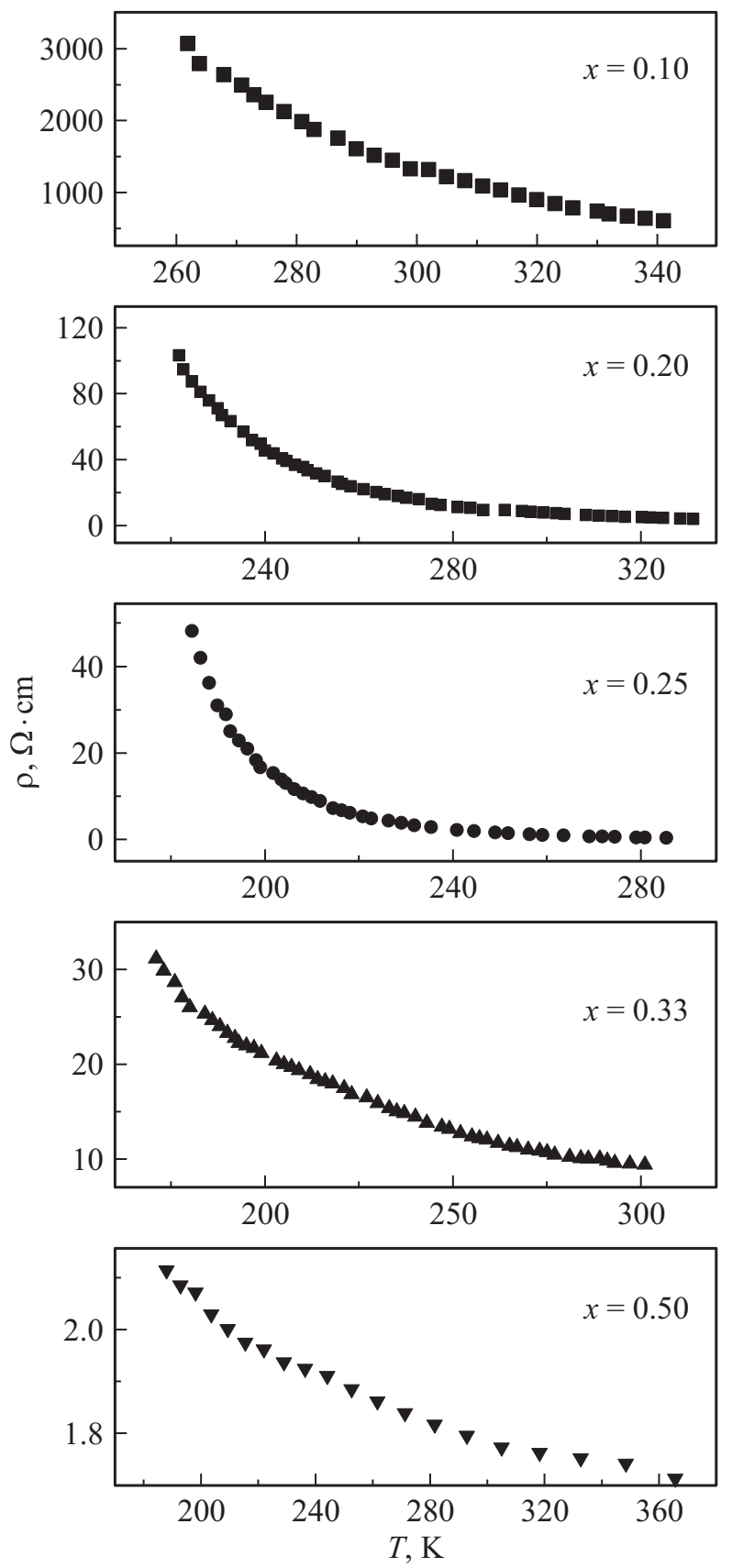

Рис. 3. Температурные зависимости удельного электросопротивления образцов $\mathrm{Fe}_{x} \mathrm{HfS}_{2}$.

тур. Значения $\Delta E$, приведенные в табл. 2 , для образцов с $x \leq 0.25$ имеют один порядок величины, но существенно уменьшаются по мере увеличения содержания железа. Учитывая высокие значения ширины запрещенной зоны в $\mathrm{HfS}_{2}$, наблюдаемые значения следует отождествить с примесным характером проводимости.

Исследование магнитных свойств соединений $\mathrm{Fe}_{x} \mathrm{HfS}_{2}$ показало, что магнитная восприимчивость $(\chi)$ у всех образцов монотонно уменьшается при повышении температуры, как это характерно для парамагнитного состояния. Тем не менее, концентрационные зависимости $\chi$ 
Таблица 2. Значения температурно-независимого вклада в магнитную восприимчивость $\chi_{0}$, парамагнитных температур Кюри $\Theta_{p}$, эффективного магнитного момента $\mu_{\text {eff, энергии }}$ активации проводимости $\Delta E$ образцов $\mathrm{Fe}_{x} \mathrm{HfS}_{2}$

\begin{tabular}{l|c|c|c|c}
\hline$x$ & $\chi_{0}, 10^{-5} \mathrm{emu} / \mathrm{g} \cdot \mathrm{Oe}$ & $\Theta_{p}, \mathrm{~K}$ & $\mu_{\text {eff, } \mu_{B}}$ & $\Delta E, \mathrm{eV}$ \\
\hline 0.1 & 0.02 & -32 & 3.12 & 0.16 \\
0.2 & 0.10 & -20 & 2.74 & 0.18 \\
0.25 & 0.32 & -11 & 1.9 & 0.2 \\
0.33 & 1.0 & -6 & 1.94 & 0.04 \\
0.5 & 0.58 & -7 & 1.51 & 0.007
\end{tabular}

при различных температурах не являются однозначными (рис. 4). В то время как при $T=300 \mathrm{~K}$ величина $\chi$ возрастает, что следовало ожидать при увеличении содержания железа, при $T=50 \mathrm{~K}$ наблюдается противоположная и даже немонотонная зависимость. Последнее может свидетельствовать о том, что магнитное состояние при низких температурах не может быть описано с позиций классического парамагнетизма. Кроме того, температурные зависимости обратной восприимчивости, как это демонстрируется на рис. 5, носят существенно нелинейный характер. Подобная особенность может быть обусловлена несколькими причинами. Одна из них заключается в значительном вкладе в измеряемую величину $\chi$, наряду с кюри-вейссовской составляющей, некоторого дополнительного вклада. В качестве второй причины можно указать наличие взаимодействия между ионами железа, как это ранее сообщалось для других подобных систем на основе дихалькогенидов титана $[11,14]$. Полученные зависимости $\chi(T)$ обрабатывались в соответствии с выражением:

$$
\chi(T)=\chi_{0}+C\left(T-\Theta_{p}\right)^{-1},
$$

где $\chi_{0}=\chi_{p}+\chi_{d}-$ член, обусловленный паулиевским парамагнетизмом электронов проводимости $\left(\chi_{p}\right)$ и диамагнитным вкладом $\left(\chi_{d}\right) ; C-$ постоянная Кюри; $\Theta_{p}-$ парамагнитная температура Кюри, знак и величина которой отражают характер возможных взаимодействий в подсистеме магнитно-активных ионов. В данной аппроксимации величина $\chi_{0}$ считалась независящей от температуры.

Значения параметра $\chi_{0}$ в уравнении (1), определенные в результате аппроксимации экспериментальных зависимостей $\chi(T)$, представлены в табл. 2. Они далее были использованы в качестве поправки для выделения из общей величины измеренной восприимчивости кюривейссовского вклада (второе слагаемое в уравнении (1)). После подобного расчета были получены линейные зависимости величины $\left(\chi-\chi_{0}\right)^{-1}$ от температуры (рис. 5) и проведено уточнение параметров $C$ и $\Theta_{p}$ в (1). Данные, представленные в табл. 2, показывают, что в образцах $\mathrm{Fe}_{x} \mathrm{HfS}_{2}$ при увеличении $x$ происходит возрастание $\chi_{0}$, где основным вкладом является паулиевская восприимчивость, определяемая свободными носителями заряда.

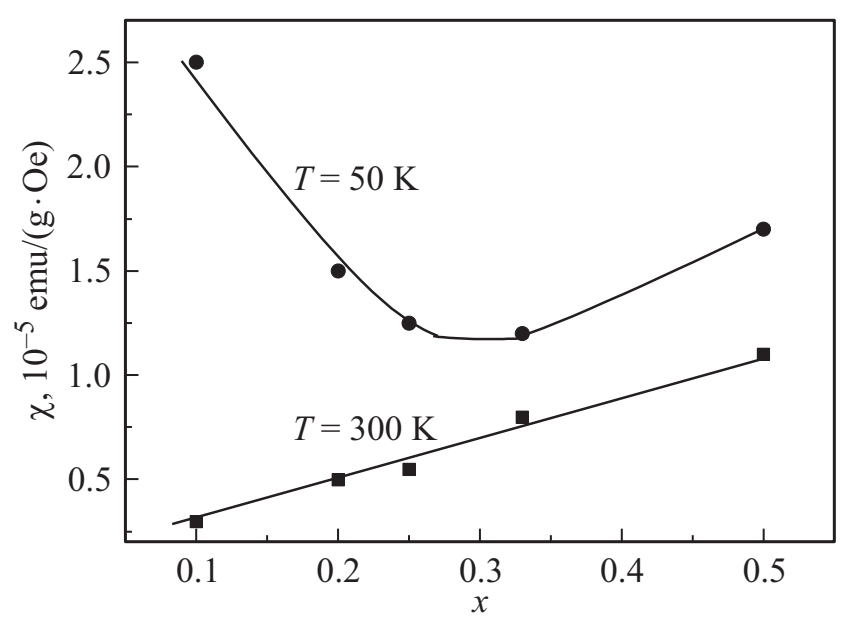

Рис. 4. Концентрационные зависимости магнитной восприимчивости $\mathrm{Fe}_{x} \mathrm{HfS}_{2}$ при различных температурах.

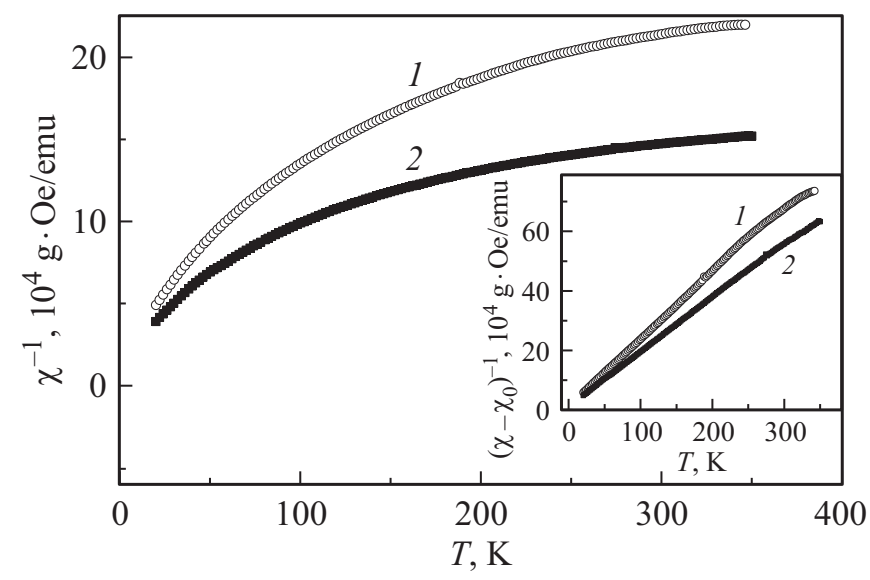

Рис. 5. Температурные зависимости величин $\chi^{-1}$ и $\left(\chi-\chi_{0}\right)^{-1}$ для $\mathrm{Fe}_{0.25} \mathrm{HfS}_{2}$ (1) и $\mathrm{Fe}_{0.5} \mathrm{HfS}_{2}$ (2).

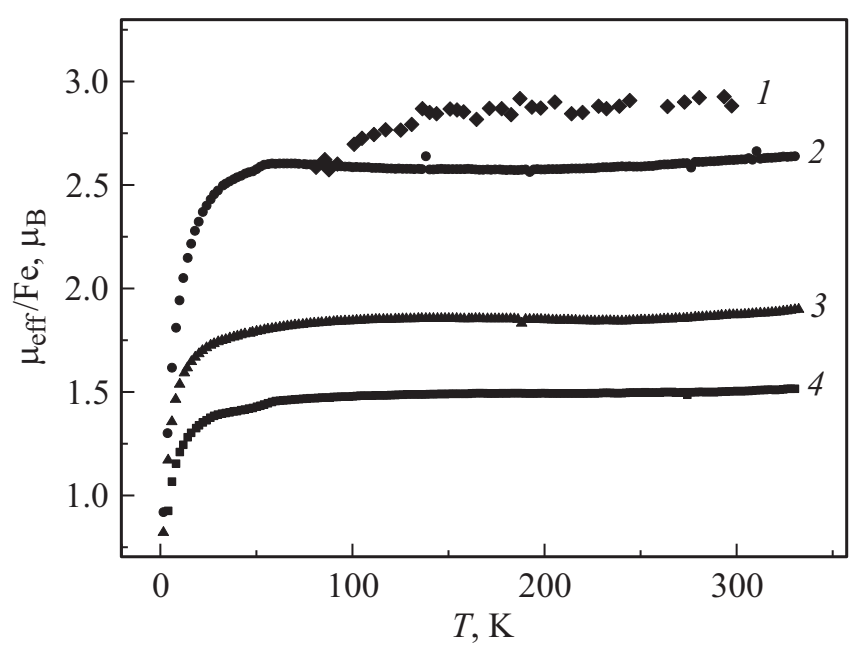

Рис. 6. Температурные зависимости эффективного магнитного момента иона железа в $\mathrm{Fe}_{x} \mathrm{HfS}_{2}: x=0.1$ (1), 0.2 (2), 0.25 (3), $0.5(4)$. 
В этой связи можно отметить качественную корреляцию между возрастанием $\chi_{0}$ и уменьшением величины электросопротивления исследованных соединений. Эффективные магнитные моменты на ион железа в целом оказываются существенно меньшими по сравнению с величинами для высокоспиновых состояний свободных ионов $\mathrm{Fe}^{2+}\left(4.9 \mu_{\mathrm{B}}\right)$ и $\mathrm{Fe}^{3+}\left(5.92 \mu_{\mathrm{B}}\right)$ и уменьшаются при увеличении содержания железа. Парамагнитные температуры Кюри имеют отрицательный знак, указывая на возможность существования в подсистеме магнитных ионов взаимодействий антиферромагнитного типа. Уменьшение $\Theta_{p}$ по абсолютной величине может быть связано с изменением баланса между ферро- и антиферромагнитными взаимодействиями. Это обстоятельство также может оказывать влияние на формирование магнитного момента. Дополнительные данные о возможности обменной связи при низких температурах могут быть получены из анализа температурных зависимостей эффективного магнитного момента на ионах железа, рассчитанного в соответствии с выражением

$$
\mu_{\mathrm{eff}}^{2}=8 \chi_{\mathrm{mol}} T / x,
$$

где $\chi_{\text {mol }}-$ молярная восприимчивость соединений, $T$ - температура, $x$ - содержание железа в $\mathrm{Fe}_{x} \mathrm{HfS}_{2}$. Результаты расчетов для образцов различного состава представлены на рис. 6. Видно, что по мере увеличения температуры значения $\mu_{\text {eff }}$ для каждого образца возрастают, асимптотически стремясь к некоторым постоянным значениям, совпадающим по величине с теми, которые представлены в табл. 2. Такой вид зависимости характерен для систем, обнаруживающих при понижении температуры антиферомагнитный характер взаимодействия между магнитоактивными ионами. Однако, на полевых зависимостях удельной намагниченности соединений с $x=0.33$ и 0.5 , полученных при $T=2 \mathrm{~K}$ в полях до $70 \mathrm{kOe}$ (рис. 7), обнаруживаются петли магнитного гистерезиса, являющиеся признаком ферромагнитного состояния. Учитывая характер концентрационной зависимости парамагнитной температуры Кюри, наличие гистерезиса может быть связано с перестройкой магнитной структуры под действием приложенного магнитного поля. Значения коэрцитивных сил для этих образцов невелики и составляют в среднем $2 \mathrm{kOe}$ для $\mathrm{Fe}_{0.33} \mathrm{HfS}_{2}$ и $1.5 \mathrm{kOe}$ для $\mathrm{Fe}_{0.5} \mathrm{HfS}_{2}$. Характерным для представленных зависимостей является очень сильный парапроцесс, так что при указанных значениях коэрцитивных сил намагниченность не достигает насыщения вплоть до значений напряженности внешнего поля $70 \mathrm{kOe}$. При этом зависимости $M(H)$ в интервале полей от 45 до $70 \mathrm{kOe}$ являются линейными. Экстраполяцией намагниченности из области высоких полей к нулевому полю были оценены значения локализованного магнитного момента на ионах железа $\left(\mu_{s}\right)$, равные $0.14 \mu_{\mathrm{B}}$ для $\mathrm{Fe}_{0.33} \mathrm{HfS}_{2}$ и $0.09 \mu_{\mathrm{B}}$ для $\mathrm{Fe}_{0.5} \mathrm{HfS}_{2}$, что значительно меньше величин $\mu_{\mathrm{eff}}$ (табл. 2). Подобные результаты были ранее получены для систем $\mathrm{Cr}_{x} \mathrm{TiSe}_{2}$ [15] и $\mathrm{Cr}_{x} \mathrm{TiTe}_{2}$ [16]. Это
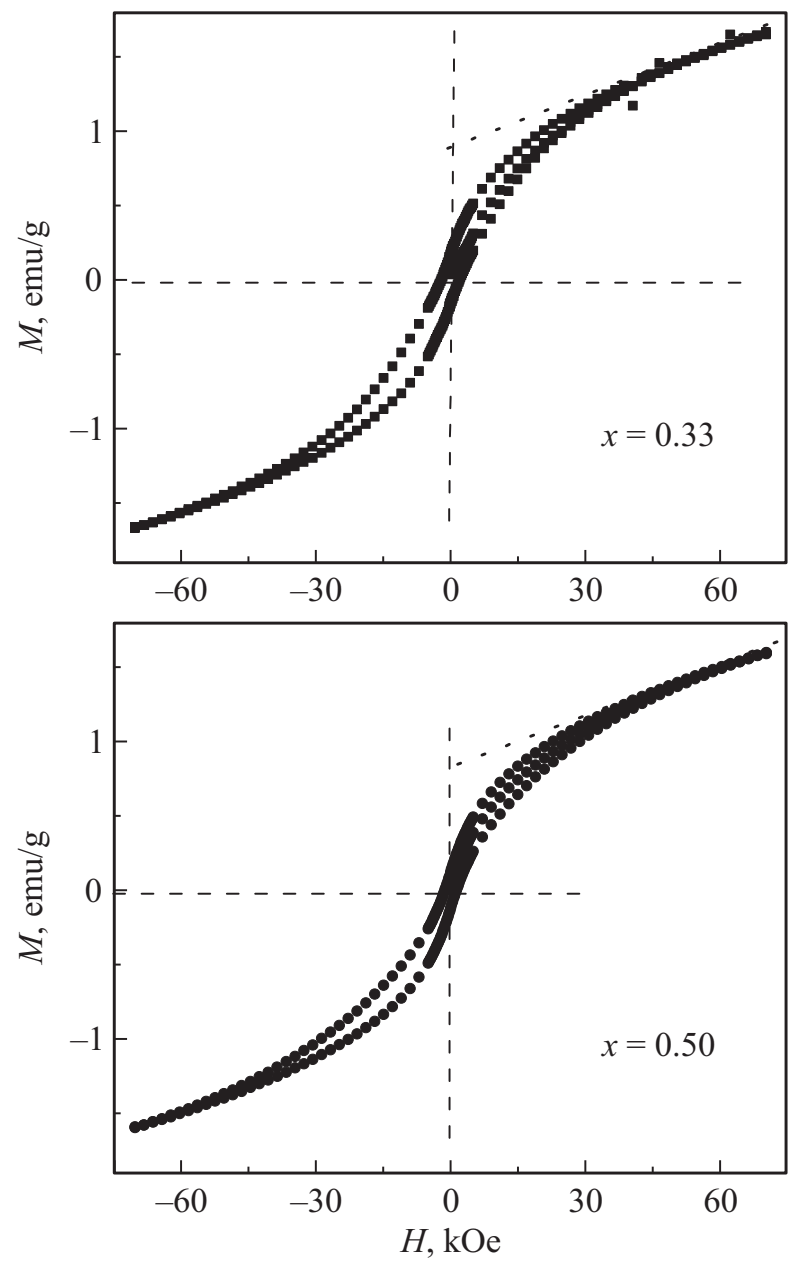

Pис. 7. Полевые зависимости удельной намагниченности $\mathrm{Fe}_{0.33} \mathrm{HfS}_{2}$ и $\mathrm{Fe}_{0.5} \mathrm{HfS}_{2}$ при $T=2 \mathrm{~K}$.

различие свидетельствует о значительной делокализации $3 d$-электронов ионов железа и показывает, что магнитное состояние соединений $\mathrm{Fe}_{x} \mathrm{HfS}_{2}$ не может быть описано только лишь в модели локализованных моментов. Можно также отметить качественное согласие между изменениями локализованного и эффективного магнитных моментов при возрастании содержания железа в исследованных материалах.

\section{4. Заключение}

Исследование влияния интеркалации атомов железа на электрические и магнитные свойства соединений $\mathrm{Fe}_{x} \mathrm{HfS}_{2}$, проведенное в настоящей работе, показало активационный характер проводимости для образцов различного состава. Уменьшение величины электросопротивления при увеличении содержания железа связывается с возрастанием концентрации носителей заряда, вносимых с ионами интеркаланта. Это может происходить и при частичной делокализации $3 d$-электронов железа. 
Магнитная восприимчивость соединений $\mathrm{Fe}_{x} \mathrm{HfS}_{2}$ возрастает при увеличении содержания интеркалированных атомов. Путем аппроксимации экспериментальных данных показано, что температурно-независимый член $\chi_{0}$, определяемый главным образом паулиевским вкладом, увеличивается с ростом $x$. Учет величины $\chi_{0}$ позволил выделить величину кюри-весовского вклада и определить значения парамагнитной температуры Кюри и эффективные моменты на ионах железа в соединениях $\mathrm{Fe}_{x} \mathrm{HfS}_{2}$. Значения $\Theta_{p}$ имеют отрицательный знак и уменьшаются по абсолютной величине по мере возрастания концентрации интеркалированного железа от $\Theta_{p}=-32 \mathrm{~K}$ для образца с $x=0.1$ до $\Theta_{p}=-7 \mathrm{~K}$ для образца с $x=0.5$. Это может указывать на то, что по мере повышения концентрации железа в дисульфиде гафния происходит постепенное изменение баланса между антиферромагнитными и ферромагнитными взаимодействиями. Полученные данные также показывают, что эффективные магнитные моменты на ионе железа для всех составов существенно меньше спиновых значений для свободных ионов и уменьшаются по мере возрастания содержания интеркаланта. Уменьшение величины момента может быть связано с уменьшением электросопротивления образцов при увеличении содержания железа и указывают на значительную гибридизацию $3 d$-электронов. Дополнительные данные, указывающие на характер возможных взаимодействий между ионами железа, были получены из температурных зависимостей эффективного магнитного момента. Значения $\mu_{\mathrm{eff}}$ возрастали по мере повышения температуры асимптотически достигая постоянных значений. Подобный вид зависимостей $\mu_{\mathrm{eff}}(T)$ характеризуют возможность антиферромагнитных взаимодействий. В то же время полевые зависимости намагниченности, измеренные при $T=2 \mathrm{~K}$ в магнитных полях до $70 \mathrm{kOe}$, обнаруживают гистерезис с достаточно малыми значениями коэрцитивных сил не превышающими $2 \mathrm{kOе}$ и линейную зависимость $M(T)$ в области больших полей. Из этих зависимостей путем экстраполяции к нулевому полю определены значения локализованных магнитных моментов на ионах железа в $\mathrm{Fe}_{0.33} \mathrm{HfS}_{2}$ и $\mathrm{Fe}_{0.5} \mathrm{HfS}_{2}$. Их изменения при увеличении содержания железа коррелируют с концентрационными изменениями эффективного магнитного момента в соединениях $\mathrm{Fe}_{x} \mathrm{HfS}_{2}$. Такие результаты могут быть связаны с изменением магнитного состояния под действием сильного магнитного поля.

\section{Список литературы}

[1] A.H. Rechak, S. Auluk. Physica B 363, 25 (2005).

[2] C. Kreis, S. Werth, R. Adelung, L. Kipp, M. Skibowski, E.E. Krasovskii, W. Schattke. Phys. Rev. B 68, 235331 (2003).

[3] M. Inoue, H.P. Hughes, A.D. Yoffe. Adv. Phys. 38, 565 (1989).

[4] Y. Tazuke, T. Takeyama. J. Phys. Soc. Jpn. 66, 827 (1997).

[5] Y. Tazuke, S. Shibata, K. Nakamura, H. Yano. J. Phys. Soc. Jpn. 64, 242 (1995).
[6] D.L. Greenaway, R. Nitsche. J. Phys. Chem. Solids 26, 1445(1965).

[7] S. Ahmed, P.A. Lee. J. Phys. D 6, 593 (1973).

[8] В.Г. Плещев, Н.В. Селезнева, Н.В. Баранов. ФТТ 54, 673 (2012).

[9] В.Г. Плещев. Н.В. Мельникова. ФТТ 56, 1702 (2014).

[10] P. Lunkenheimer, A. Loidl. Phys. Rev. Lett. 91, 207601 (2003).

[11] Н.В. Баранов, В.Г. Плещев, Е.М. Шерокалова, Н.В. Селезнева, А.С. Волегов. ФТТ 53, 654 (2011).

[12] H. Negishi, A. Shoube. H. Takahashi, Y. Ueda, M. Sasaki, M. Inoue. J. Magn. Magn. Mater. 67, 179 (1987).

[13] Н.В. Селезнева, Н.В. Баранов, В.Г. Плещев, Н.В. Мушников, В.И. Максимов. ФТТ 58, 269 (2011).

[14] Н.В. Баранов, В.Г. Плещев, А.Н. Титов, В.И. Максимов, Н.В. Селезнева, Е.М. Шерокалова. Нанотехника 3, 15 (2008),

[15] V.G. Pleschov, N.V. Baranov, A.N. Titov, K. Inoue, M.I. Bartashevich, T. Goto. J. Alloys Comp. 320, 13 (2001).

[16] В.Г. Плещев, А.В. Королев, Ю.А. Дорофеев. ФТТ 46, 282 (2004). 